\title{
EXPERIMENTAL SHEAR RESISTANCE EVALUATION OF ORDINARY AND PERFOBOND Y-SHAPED SHEAR CONNECTORS
}

\author{
M.A Dabaon ${ }^{1}$, M.H. El-Boghdadi ${ }^{2}$, O.F. Kharoob ${ }^{3}$ and A.H. El Gendy ${ }^{4}$ \\ ${ }^{1}$ Professor, Structural Engineering Department, Tanta University, Egypt. \\ E-mail: m_dabaon@yahoo.com \\ ${ }^{2}$ Assoc. Professor, Structural Engineering Department, Tanta University, Egypt. \\ E-mail: mhboghdadi@yahoo.com \\ ${ }^{3}$ Assoc. Professor, Structural Engineering Department, Tanta University, Egypt. \\ E-mail: omnia_m102010@yahoo.com \\ ${ }^{4}$ Demonstrator, Structural Engineering Department, Tanta University, Egypt. \\ E-mail: eng_elgendy89@yahoo.com
}

\begin{abstract}
Composite structures refer to two load carrying structural members that are integrally connected and deforming as a single unique unit using shear connectors. The use of shear connectors enhances the development of longitudinal shear forces at the steel-concrete interface. The objective of this research is to study the structural behavior of a proposed separated Y-shaped shear connector. The suggested investigated Y-shaped shear connector is intended to be an improvement to the structural response of the conventional perfobond shear connector. Accordingly, this paper carries out six push-out tests on the separated Yshaped shear connector according to EC4. The experimental work is performed in the Reinforced Concrete and Heavy Structures Laboratory at the Structural Engineering Department, Tanta University, Egypt. The key parameters affecting the behavior of the shear connector in the current investigation are the height, the thickness and the Y-shaping of the shear connector. Also, the effect of hole existence is investigated. Other parameters such as the length of the connector, the concrete strength and the slab geometry are kept the same for all specimens. Based on the performed tests, the results show that the proposed separated Yshaped shear connector has higher shear resistance than that of the conventionalperfobond shear connector. Also, the proposed connector shows better ductile behavior than the conventional perfobond connector. Moreover, results proved that increasing the connector thickness has a significant effect on the connector behaviour by increasing its shear resistance. Furthermore, as the height of the connector increases, the shear capacity increases. Finally, from the presented results it is clarified that the proposed separated Yshaped connector is better and more economical than the conventional perfobond connector.
\end{abstract}

Keywords: Push-out test, Shear connectors, Perfobond connectors, Y-shaped shear connectors

\section{Introduction}

Throughout the last decades composite structures combining the steel and concrete advantages have been extensively used in buildings and bridges. Steel provides the required resistance to tension stresses, while concrete has a remarkable resistance to compressive stresses and enhances the stability and fire capacities of the steel section. The connection between the steel section and the 
concrete slab provides the required composite behavior, making the two elements to work as one piece. The shear connector assures the shear transfer between the steel section and the concrete slab, enabling a composite action to develop. The Nelson or Stud connector, developed during the 1940's by Nelson Stud Welding Company, is the most extensively used and known shear connector; see Fig.1.a. It has many advantages like being automatically welding, well defined structural mechanism and simple design procedures [1-3]. Despite that it has some disadvantages; the welding process requires specific welding equipment and high power generator in site. Moreover, large number of connectors is required, beside that it has some limitations in structures submitted to fatigue [4]. Recently, several shear connectors have been proposed and used in composite structures like the Channel connector [3,5], the Spiral connector [6] and the Hilti connector [7]; see Fig.1.b,c.

In order to overcome the disadvantages of the Nelson or stud connectors, in 1987 a German company Leonhardt, developed a new shear connector called Perfobond connector [8]; see Fig 1.d. The basic design purpose of this connector is to mobilize the elastic deformations for service loads. Several authors studied the behavior and application of the Perfobond connectors proposing different models to predict its shear resistance [9-16]. However these shear connectors have high shear resistance, it also has some disadvantage such as its high rigidity that leads to a brittle fracture behavior caused by fracture of concrete, low workability and difficulty to position the lower reinforcement of the slab as the steel bars have to cross the connector openings. Thus, developing the perfobond shear connectors a new connector was proposed to improve its workability called the CR connector [17]; see Fig.1.e. In 2013, the Y-type perfobond rib shear connector was proposed to improve both the ductility and resistance of the conventional perfobond rib shear connector [18-20].

Based on the above background, the focus of the present paper is on a separated or single unit Yshaped shear connector and its structural behavior according to its geometry. This connector is a development of the ordinary separated perfobond shear connector, improving its ductility, workability and its resistance. In addition, using separated or single unit Y-shaped shear connectors possess a potential advantage over the ribbed connector in terms of material and fabrication cost. The present tests in this study are the push-out test defined in the Eurocode 4 [21]. The behavior of the connector is evaluated depending on the relationship between the load and the relative slip obtained from the experimental results.

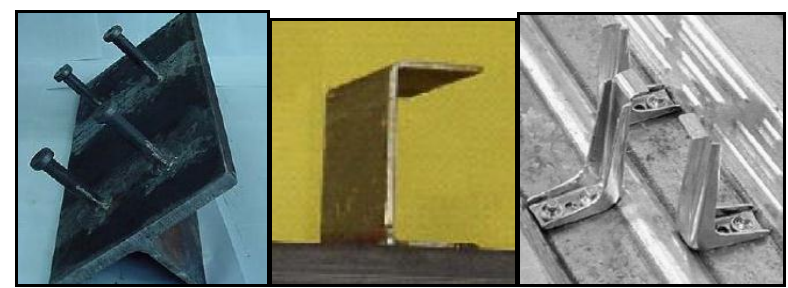

(a) Stud Connector (b) Channel Connector (c)Hiliti Connector [15]

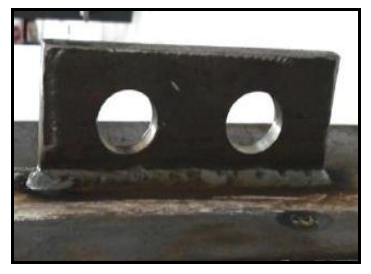

(d) Perfobond connector

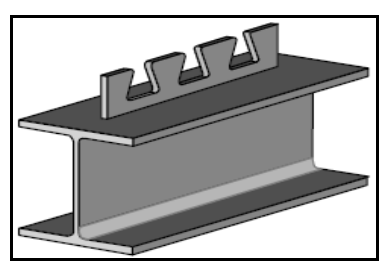

(e) CR Connector [17]

Fig.(1) Diffent types of shear connectors 


\section{Experimental Testing 2.1 Push-out test}

According to the Eurocode 4 [21], the push-out specimen consists of short length steel-I section which is held vertically and connected to two small concrete slabs by using shear connectors. The details of the "standard push-out test" given in Eurocode 4 [21] are shown in Fig.2. The load is applied to the upper end of the steel beam using a compression-testing machine. The first stage of loading includes 25 cycles of loading/unloading, ranging between $5 \%$ and $40 \%$ of the expected failure load. Subsequently, the load is increased at a constant rate until the failure load. The test is continued until the load value drops to $20 \%$ below the ultimate load. Slip between the steel section and the two concrete slabs is measured at several points, and the average slip value is plotted against the load per connector obtaining the load-slip curve for the tested connector [14, 21, 22].

The slip capacity of the connector $\left(\delta_{\mathrm{u}}\right)$ is taken as the highest measured slip value corresponding to the characteristic load $\left(\mathrm{P}_{\mathrm{Rk}}\right)$, as shown in Fig.2. The characteristic load $\left(\mathrm{P}_{\mathrm{Rk}}\right)$ is taken as the minimum failure load, divided by the number of shear connectors and reduced by $10 \%$. The characteristic slip denoted by $\left(\delta_{\mathrm{uk}}\right)$ is taken as the slip capacity of the connector $\left(\delta_{\mathrm{u}}\right)$ reduced by $10 \%[14,21]$.

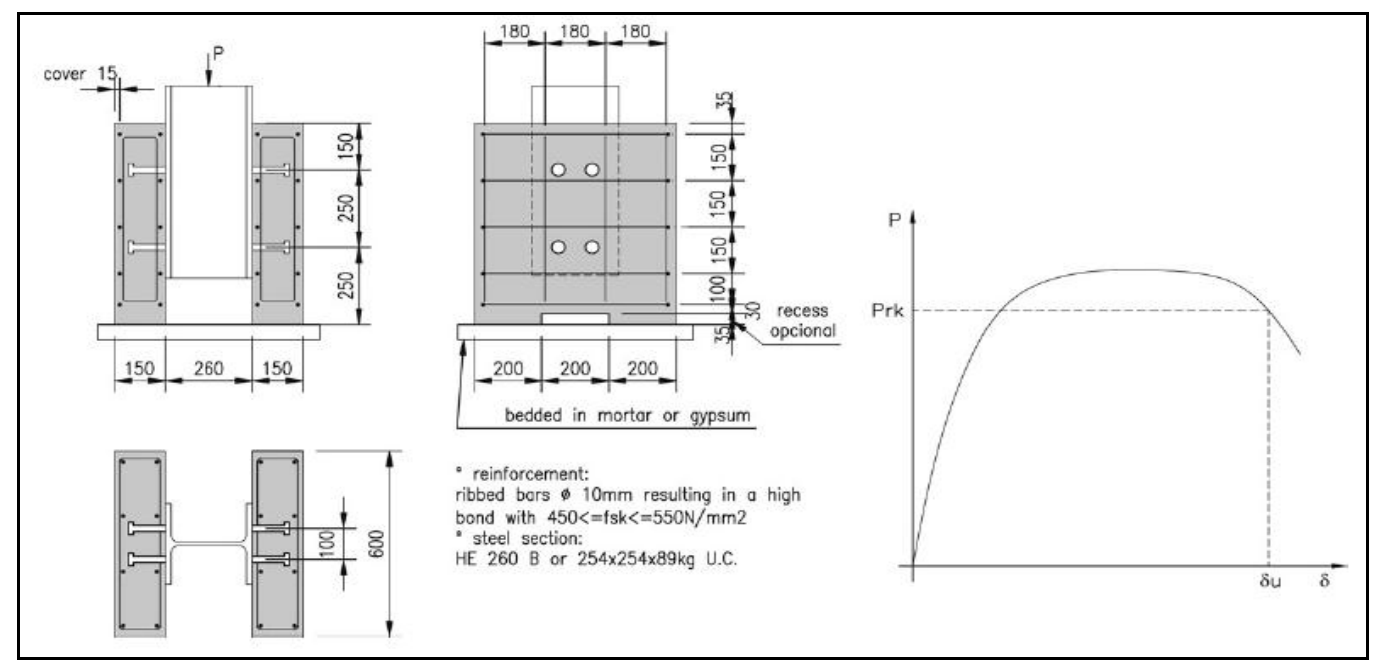

Fig.(2) Push-out test according

As it is difficult to use the values of $P_{\mathrm{Rk}}$ and $\delta_{\mathrm{u}}$ to express the ductility of the shear connector. The ratio of $\left(\delta_{\mathrm{u}} / \delta_{\mathrm{m}}\right)$ can be used for expressing this ductility, where $\left(\delta_{\mathrm{m}}\right)$ is the slip value corresponding to the test maximum load $\left(\mathrm{P}_{\max }\right)$, see Fig.3. As it is clear the larger this ratio $\left(\delta_{\mathrm{u}} / \delta_{\mathrm{m}}\right)$, the bigger the ductility of the shear connector.

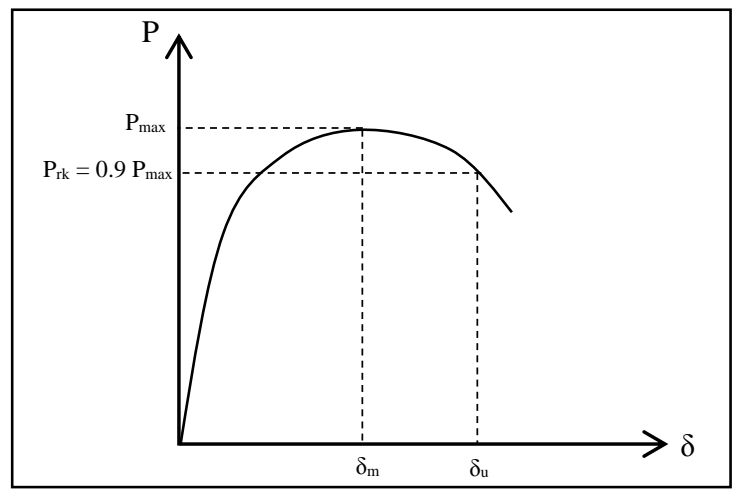

Fig.(3) Determination of $\left(\delta_{u}\right)$ and 


\subsection{Testing program}

A total of six push-out tests are carried out (two ordinary straight plates and four Y-shaped specimens). Following the notation define in Fig.4, the dimensions of each specimen are listed in Table 1. The test specimens were labeled in such a way that the type of the connector, the angle of the Y-shape, the thickness and the height of the connector are defined easily from the label. The first letter indicates the connector type, where the prefix letter " $\mathrm{S}$ " refers to straight connector with angle $0^{\circ}$ and "Y" refers to $45^{\circ} \mathrm{Y}$-shaped connector. The next letter, " $\mathrm{O}$ " refers to a non-holed connector and " $\mathrm{P}$ " refers to a perfobond connector (connector with a single $20 \mathrm{~mm}$ hole). The following digit (6/8) indicates the thickness of the connector. The last three digits (140/160) define the height of the connector. For example specimen SP4 with a label (YP-8-160) means that it is a Y-shaped connector, with an angle $45^{\circ}$, having a single hole, with diameter $20 \mathrm{~mm}$. The thickness of that connector is $8 \mathrm{~mm}$ and its height is $160 \mathrm{~mm}$.

Table (1) Dimensions of the shear connectors

\begin{tabular}{|c|c|c|c|c|c|c|}
\hline Specimen & Label & $\begin{array}{c}\mathbf{L} \\
(\mathbf{m m})\end{array}$ & $\begin{array}{c}\mathbf{H} \\
(\mathbf{m m})\end{array}$ & $\begin{array}{c}\mathbf{t} \\
(\mathbf{m m})\end{array}$ & $\boldsymbol{\theta}$ & $\begin{array}{c}\boldsymbol{\emptyset} \\
(\mathbf{m m})\end{array}$ \\
\hline SP1 & SO-8-160 & 100 & 160 & 8 & $0^{\circ}$ & 0 \\
\hline SP2 & SP-8-160 & 100 & 160 & 8 & $0^{\circ}$ & 20 \\
\hline SP3 & YO-8-160 & 100 & 160 & 8 & $45^{\circ}$ & 0 \\
\hline SP4 & YP-8-160 & 100 & 160 & 8 & $45^{\circ}$ & 20 \\
\hline SP5 & YP-6-160 & 100 & 160 & 6 & $45^{\circ}$ & 20 \\
\hline SP6 & YP-8-140 & 100 & 140 & 8 & $45^{\circ}$ & 20 \\
\hline
\end{tabular}

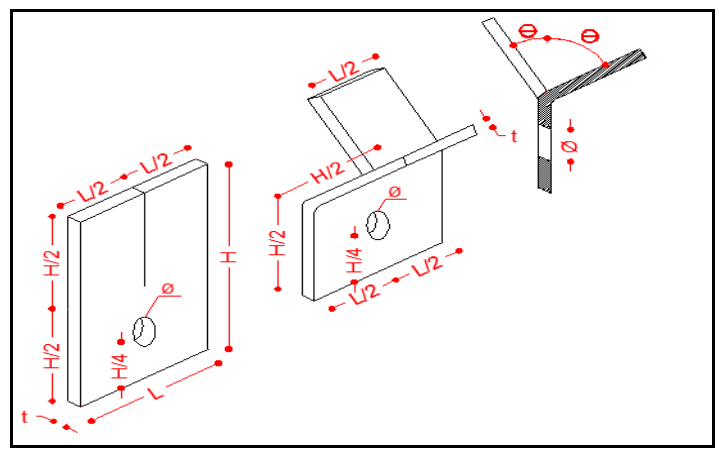

Fig.(4) Nomenclature of connector

\subsection{Fabrication of specimens}

The test specimens are fabricated according to EC4 [21] specifications, as shown in Fig.2. The specimen consists of a $650 \mathrm{~mm}$ steel section (HEA260) connected to two concrete slabs 650x600 $\mathrm{mm}$ with thickness $200 \mathrm{~mm}$, as shown in Fig.5, using the tested shear connectors.

The reinforcement meshes of the concrete slabs are assembled using $10 \mathrm{~mm}$ corrugated bars. Then for each specimen four connectors are welded to the steel beam by certified welders. The formworks are made of cold formed steel plates, to get a smooth finished surface and to guarantee the specified slab dimensions. After that the steel beam and the connectors are greased to minimize the friction force between the concrete and the steel sections. Finally, the concrete is bored and compacted using mechanical vibratos; see Fig.6. 


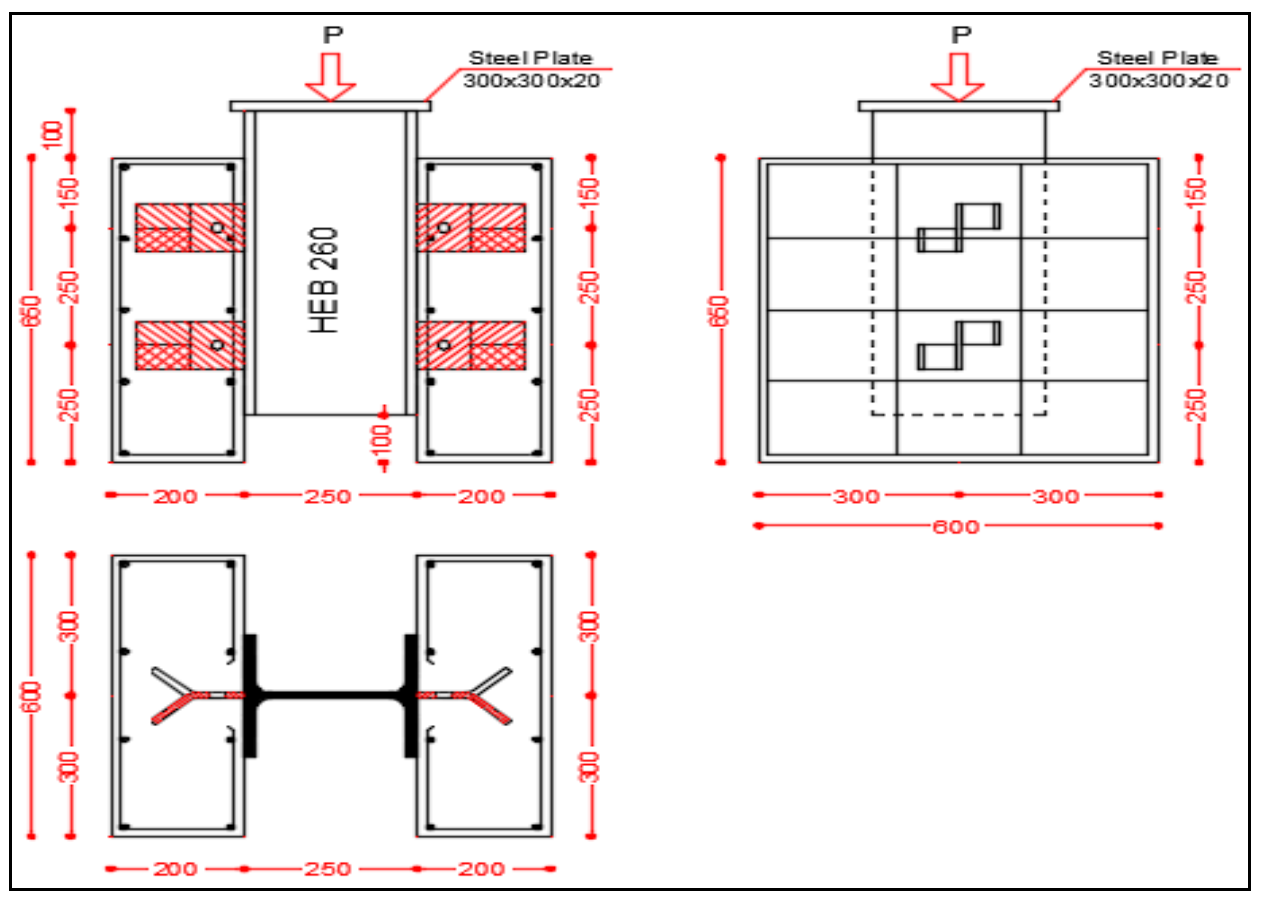

Fig.(5) Test specimens configurations

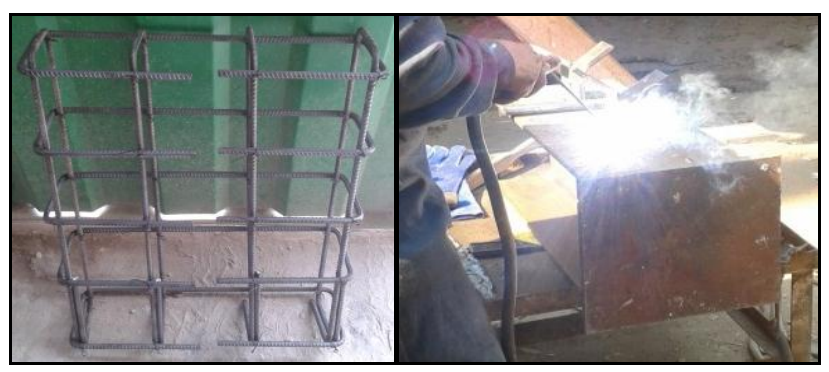

(a) Assembling the RFT (b) Welding the
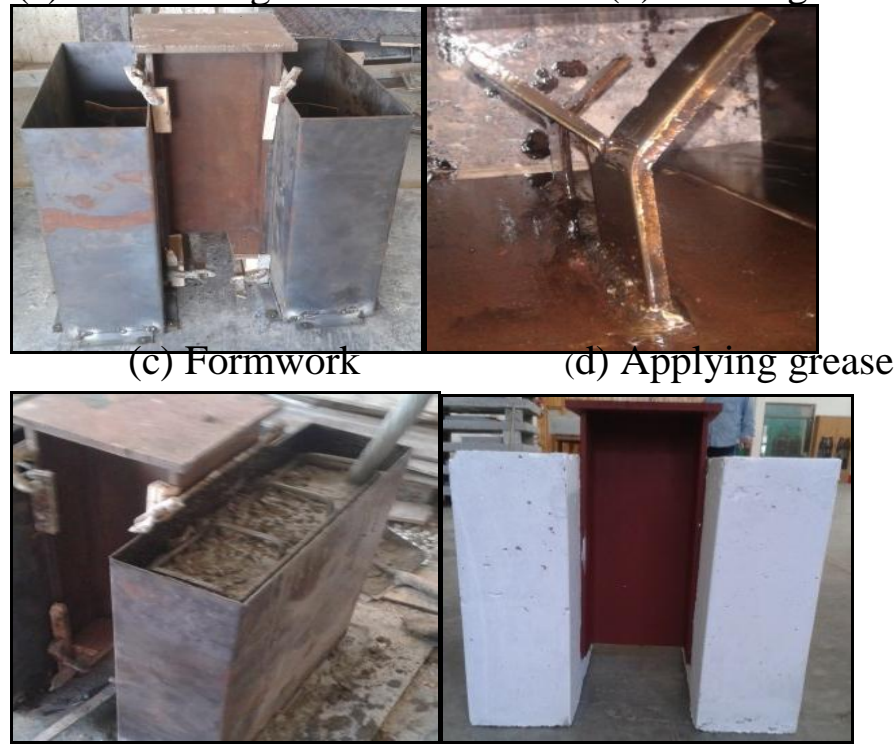

(e) Concrete pouring and

(f) Finishing the specimen

Fig.(6) Fabrication process of test 


\subsection{Material properties}

The steel sections are HEA260 with steel S275, with minimum nominal yield stress of $275 \mathrm{MPa}$, according to EN10025. The shear connectors are fabricated from the same steel plates for each thickness using steel S355 steel plates, with minimum nominal yield stress of $355 \mathrm{MPa}$, according to EN10025. The used reinforcement rebars are made from $10 \mathrm{~mm}$ diameter corrugated bars using steel S500, with minimum nominal yield stress of $500 \mathrm{MPa}$, according to EN1992-1-1, as prescribed by the Eurocode 4, Annex B [21].

The concrete compressive strength is the same for all test specimens as they all are made from the same admixture. In order to determine the concrete compressive strength ten cylinders (150 mm diameter and $300 \mathrm{~mm}$ height) and ten cubes $(150 \times 150 \times 150 \mathrm{~mm})$ are prepared while casting the concrete slabs for push-out specimens. These samples are tested at the same age of the push-out tests. The tested concrete cubic strength $\left(f_{c u}\right)$ is $25.33 \mathrm{MPa}$ and its cylinder strength $\left(f_{c}\right)$ is $20.5 \mathrm{MPa}$ which corresponds to a nominal C20/25 class according to Eurocode 2 [23].

\subsection{Test setup and instrumentations}

Fig.7 and Fig.8 illustrate the test layout and specimens instrumentations. The vertical load is applied monotonically using a hydraulic testing machine with $1000 \mathrm{kN}$ capacity. Two $100 \mathrm{~mm}$ linearvariable differential transducers (LVDTs) are installed vertically to measure the slip between the steel beam and the concrete slabs at a regular period of time. Moreover, another vertical LVDT is used at the center of the steel beam to check the loading conditions and displacement of the steel section. Additionally, two $50 \mathrm{~mm}$ LVDTs are located to measure the lateral displacement of the concrete slabs.

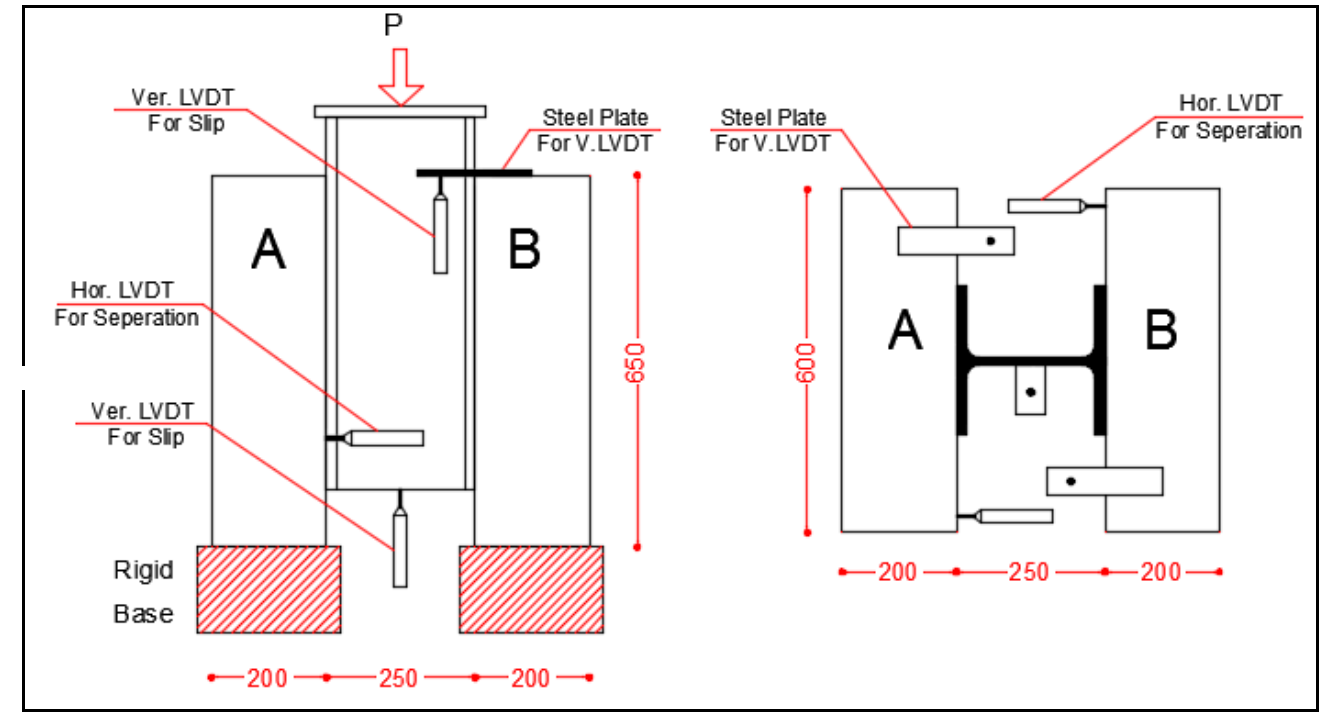

Fig.(7) Instrumentation layout 

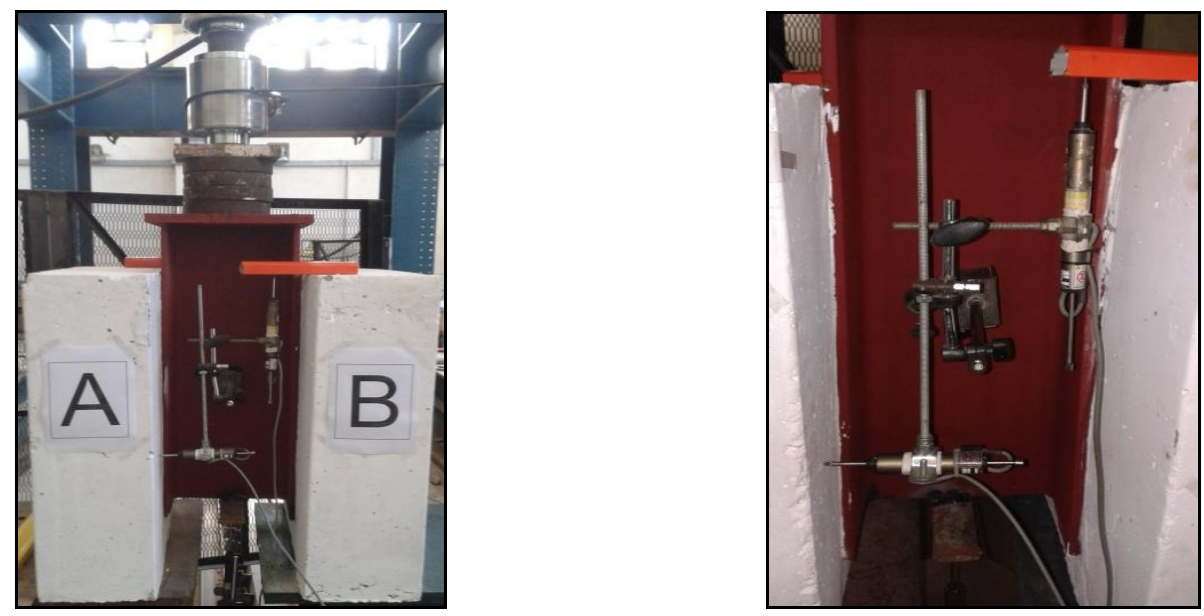

Fig.(8) Test setup and

\section{Results and discussion}

\subsection{General results}

The results of the performed push out tests are summarized in Table 2. This table gives the test failure load per connector $\left(\mathrm{P}_{\max }\right)$ and the characteristic load per connector $\left(\mathrm{P}_{\mathrm{rk}}\right)$, which equals $0.9 \mathrm{P}_{\max }$ according to EC4 [21]. In addition, the corresponding slip capacity $\left(\delta_{\mathrm{u}}\right)$ and the characteristic slip capacity $\left(\delta_{\mathrm{uk}}\right)$, which equals $0.9 \delta_{\mathrm{u}}$ according to EC4 [21] are given. In order to describe the ductility of the tested specimens, the ratios between the slip capacities $\left(\delta_{u}\right)$ to the slip at the maximum load $\left(\delta_{\mathrm{m}}\right)$ are listed in Table 2.

Table (2) Push-out tests results

\begin{tabular}{|c|c|c|c|c|c|c|c|}
\hline \multirow{2}{*}{$\boldsymbol{S P}$} & \multirow{2}{*}{ Label } & $\boldsymbol{P}_{\max } /$ connector & $\boldsymbol{P}_{\boldsymbol{r k}} /$ connector & $\boldsymbol{\delta}_{\boldsymbol{u}}$ & $\boldsymbol{\delta}_{\boldsymbol{u} \boldsymbol{k}}$ & $\boldsymbol{\delta}_{\boldsymbol{m}}$ & \multirow{2}{*}{$\boldsymbol{\delta}_{\boldsymbol{u}} / \boldsymbol{\delta}_{\boldsymbol{m}}$} \\
\cline { 3 - 8 } & & $\boldsymbol{k N}$ & $\boldsymbol{k N}$ & $\boldsymbol{m m}$ & $\boldsymbol{m m}$ & $\boldsymbol{m m}$ & \\
\hline SP1 & $\mathbf{S O - 8 - 1 6 0}$ & 114 & 103 & 2.79 & 2.51 & 1.99 & 1.40 \\
\hline $\boldsymbol{S P 2}$ & $\mathbf{S P - 8 - 1 6 0}$ & 128 & 116 & 2.50 & 2.25 & 1.81 & 1.38 \\
\hline SP3 & YO-8-160 & 147 & 132 & 4.61 & 4.15 & 1.48 & 3.11 \\
\hline SP4 & YP-8-160 & 158 & 142 & 4.57 & 4.11 & 1.82 & 2.51 \\
\hline SP5 & $\mathbf{Y P - 6 - 1 6 0}$ & 114 & 102 & 5.99 & 5.40 & 2.28 & 2.63 \\
\hline SP6 & $\boldsymbol{Y P - 8 - 1 4 0}$ & 137 & 123 & 4.51 & 4.06 & 1.87 & 2.41 \\
\hline
\end{tabular}

From Table 2, it can be observed that, the proposed separated Y-shaped connector has better resistance and remarkable ductility compared to the ordinary perfobond connector. Moreover, the results show that, adding a hole increases the connector capacity, but decreases its ductility.

Furthermore, the decreasing of the thickness of the connector decreases its capacity and increases its ductility. On the other hand, decreasing the height of the connector decreases both the load capacity and ductility of the connector.

\subsection{Influence of Y-shaping}

Herein, a comparison between using the separated Y-shaped connectors and the conventional perfobond connectors is applied; see Fig.9 and Fig.10.

Fig.9.a shows the load-slip curves of specimen (YO-8-160) and (SO-8-160). Also, the load-slip curves of specimens (YP-8-160) and (SP-8-160) are plotted in Fig.9.b. It can be observed that, the shear capacity of the separated Y-shaped shear connector is higher than the perfobond shear 
connector due to the increasing of bearing area. As can be seen in Table 2 the increasing in shear capacity $\left(\mathrm{P}_{\mathrm{rk}}\right)$ between SP1 and SP3 is about $28 \%$. On the other hand, the increasing of shear capacity $\left(\mathrm{P}_{\mathrm{rk}}\right)$ between SP2 and SP4 is about $23 \%$.

Furthermore, it can be seen that, using the separated Y-shaped connectors increases noticeably the initial stiffness comparing to the ordinary perfobond connectors. With respect to the slip capacity, it is found that using the Y-shaping increases its value by about $65 \%$ and $82 \%$ for the drilled and nondrilled connectors. This remarkable increase is due to the improved behavior of the connector beyond the peak (failure) load; the Y connectors present a good load bearing capacity after reaching its failure load with a slower loss of load unlike the ordinary perfobond connectors which lose its load suddenly with a rapid loss rate of load.

Concerning the ductility, from Table 2 it can be seen that the ductility ratio $\left(\delta_{\mathrm{u}} / \delta_{\mathrm{m}}\right)$ increases at least by $82 \%$ due to the $\mathrm{Y}$-shaping effect.

(a)

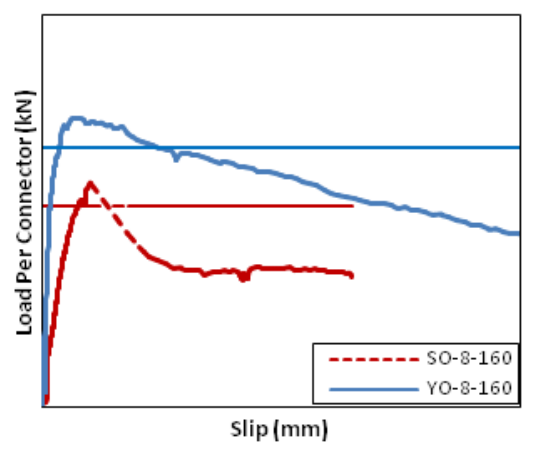

(b)

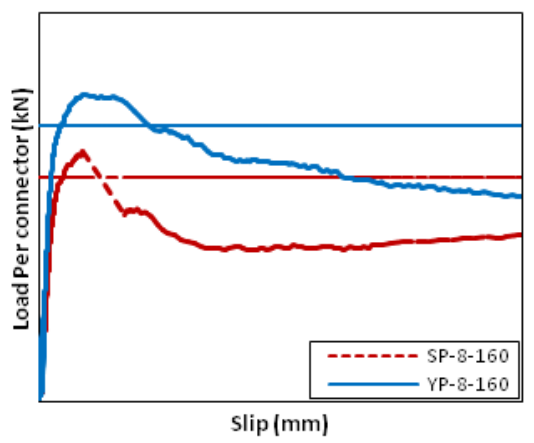

Fig.(9) Load-Slip curves showing the influence

(a)

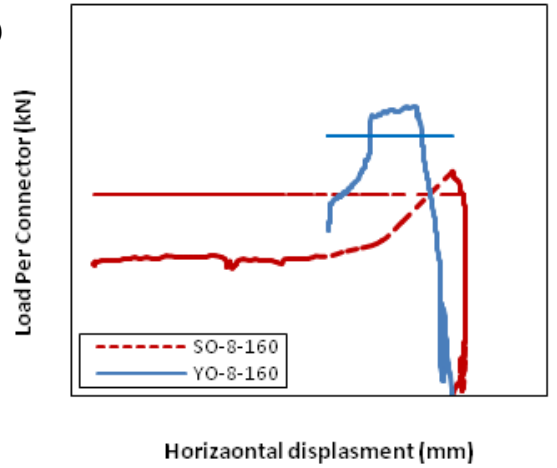

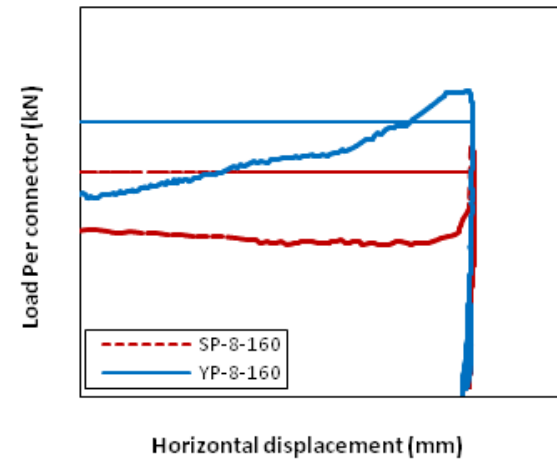

(b)

Fig.(10) Uplift curves showing the influence

Fig.10 presents the relationship between the load and the horizontal displacement (uplift) for the Yshaped and the perfobond connectors, it can be seen that the $\mathrm{Y}$-shaping improves the connectors behavior after peak load due to the effect of the arms of the Y-shape.

\subsection{Influence of thickness variation}

In this sub-section, a comparative study is presented for specimens (YP-8-160) and specimen (SP6-160) in order to explain the influence of varying the thickness of the Y-shaped shear connectors; as shown in Fig.11. Overall, the same trend is observed for the two specimens. However, increasing the thickness by $2 \mathrm{~mm}$ enhances the connection shear capacity by about $39 \%$ and decreases its slip capacity by about $24 \%$. Despite that, the total loss of the connection ductility is not remarkable. 
In addition, it can be observed that this increase improves the post peak behavior with higher load capacity and also has a remarkable improvement to the initial stiffness of the Y-connector.

(a)

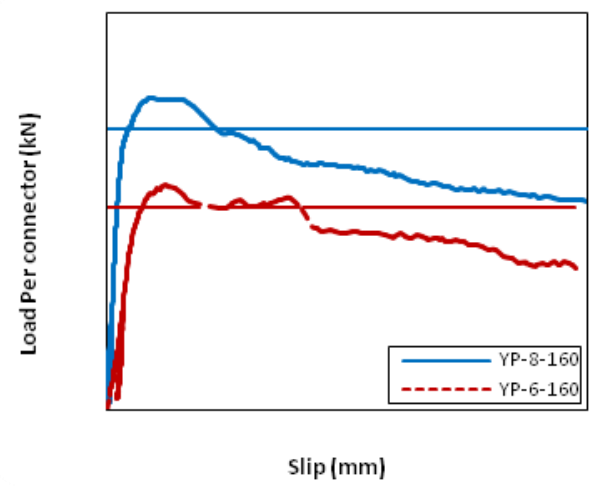

Fig.(11) Load-Slip curves showing the influence of

\subsection{Influence of height variation}

The influence of height variation for the separated $\mathrm{Y}$-shaped connectors is performed here by comparing the behavior of specimen (YP-8-160) and specimen (YP-8-140); see Fig.12. As before, it can be seen that they also have the same behavior. The results show that increasing the height of the connector by $20 \mathrm{~mm}$ increases the shear capacity of the connector by about $16 \%$ with some gain of the connection slip capacity and ductility.

On the other hand, increasing the height of the connector improves the load carrying capacity after the failure load and enhances the initial stiffness of the Y-connector.

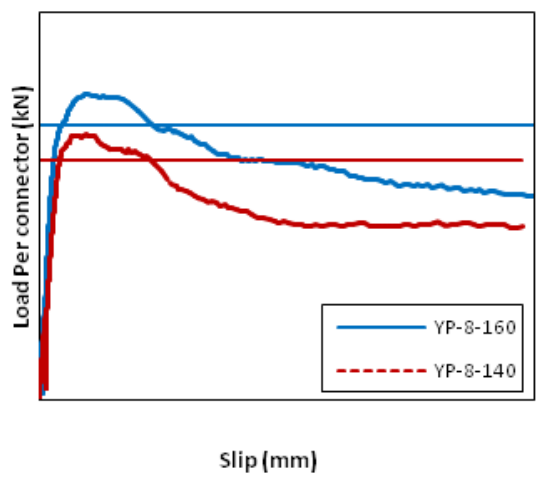

Fig.(12) Load-Slip curves showing the influence of

\subsection{Influence of a hole existence}

In order to study the effect of a hole existence in the shear connector, a comparative study is performed here between the Y-shaped and the ordinary perfobond connectors without holes and with a single hole. Fig.13.a presents the load-slip curves of specimens (SO-8-160) and (SP-8-160). Also Fig.13.b shows the load-slip curves of specimens (YO-8-160) and (YP-8-160). It can be concluded that adding a single hole increases the load capacity by about $12 \%$ for the ordinary perfobond connector and $7 \%$ for the Y-shaped connectors. This slight increase of load capacity for the Yshaped connector returns to the high load capacity of this connector unlike the ordinary perfobond connectors. 
From Table 2, it can be seen also that the existence of a hole decreases the connection slip capacity and ductility.

So if no transverse rebars are used to pass through the connector, there is no need to make a hole in the Y-shaped connector as its contribution to capacity of the shear connector is not significant unlike the perfobond connector as it is essential to have at least one hole to guaranty an adequate behavior as stated before by Candido-Martins, Costa-Neves and S. Vellasco [16].

(a)

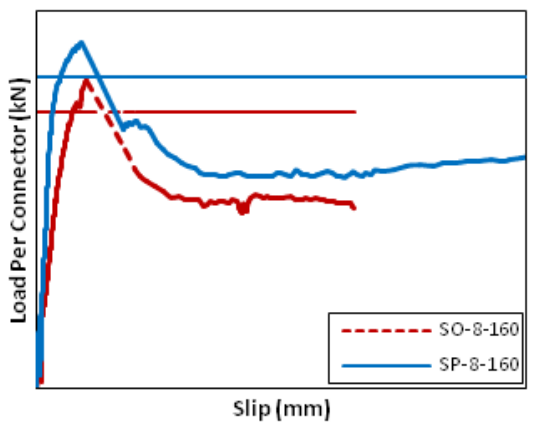

(b)

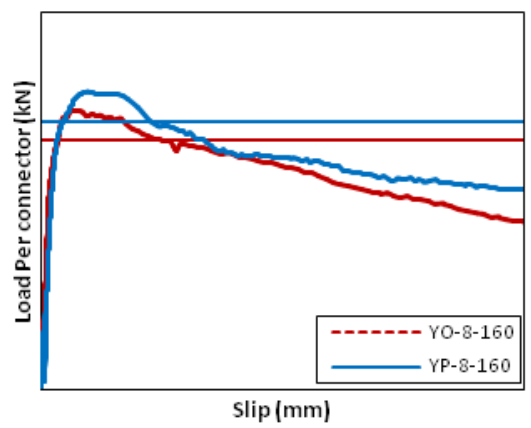

\subsection{Failure modes}

Fig.(13) Load-Slip curves showing the influence a hole

The failure modes of all specimens are related to concrete failure. For all specimens an initial vertical crack develops at the lower part of the concrete slab under the position of the connectors and grows thicker by increasing the load as shown in Fig.14.a. Only for the Y-shaped connectors this vertical crack is accompanied by more small cracks, as shown in Fig.14.b, which means a better load distribution through the concrete slab.

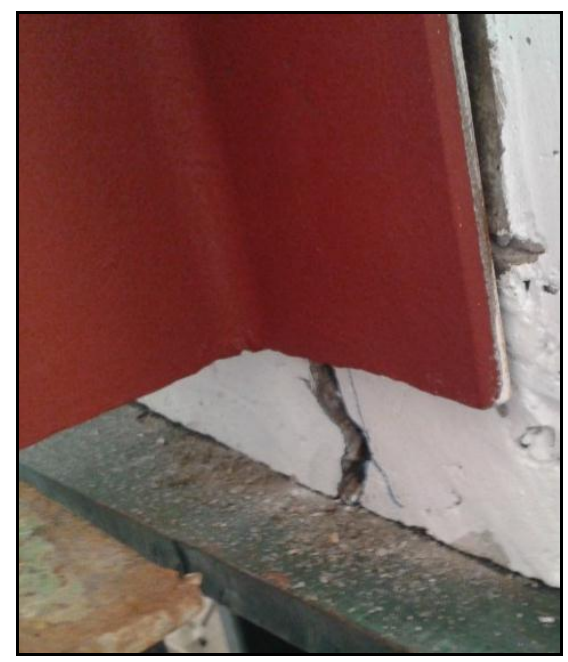

(a) Perfobond Connectors

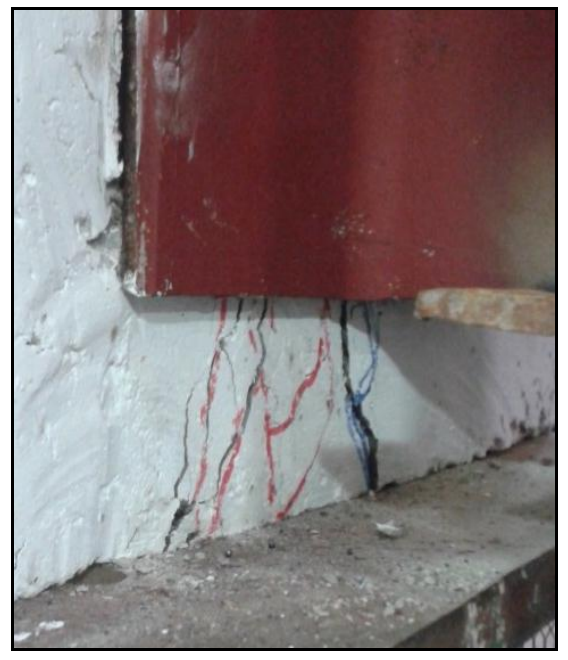

(b) Y-shaped Connectors

Fig.(14) Crack pattern at the lower part of the concrete

Another crack is observed at the upper surface of the concrete slab which grows thicker as the load increases too. This crack pattern differs by varying the connector type as it is straight for the perfobond connector and taking a Y shape for the Y-Shaped connector as shown in Fig.15. 


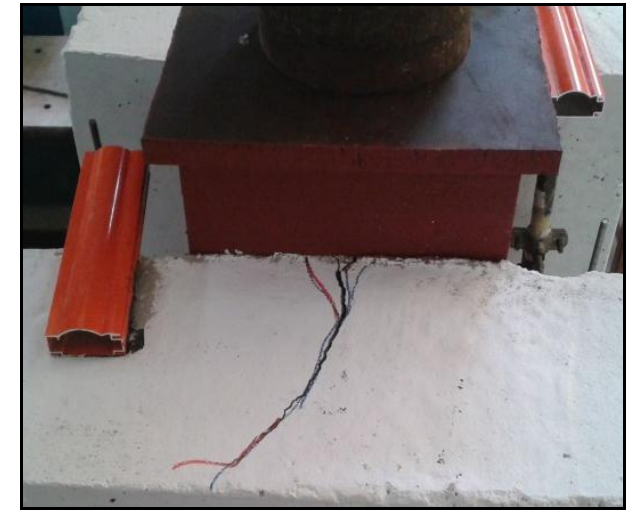

(a) Perfobond Connectors

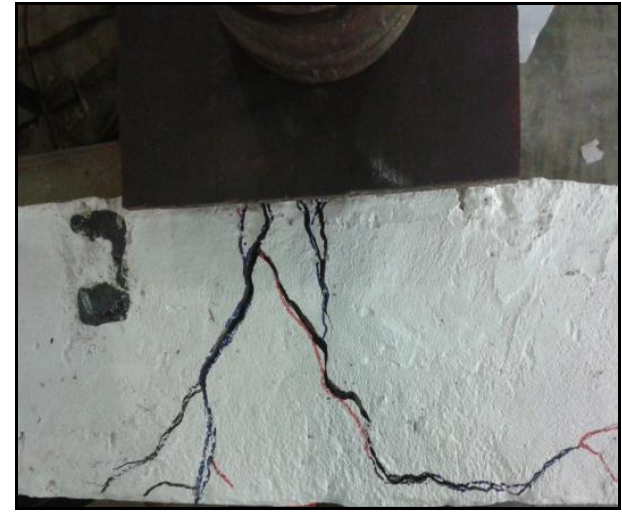

(b) Y-shaped Connectors

Fig.(15) Crack pattern at the upper surface of the

Concerning the separation between the steel beam and the concrete slab, from Fig.16, it can be seen that a large displacement occurs for the straight connectors unlike the Y-shaped connectors which have a small value of separation.

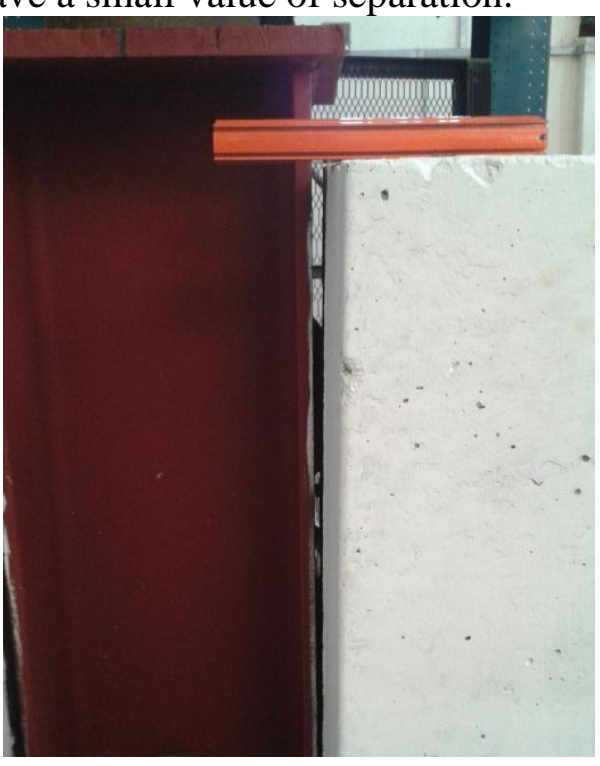

(a) Perfobond Connectors

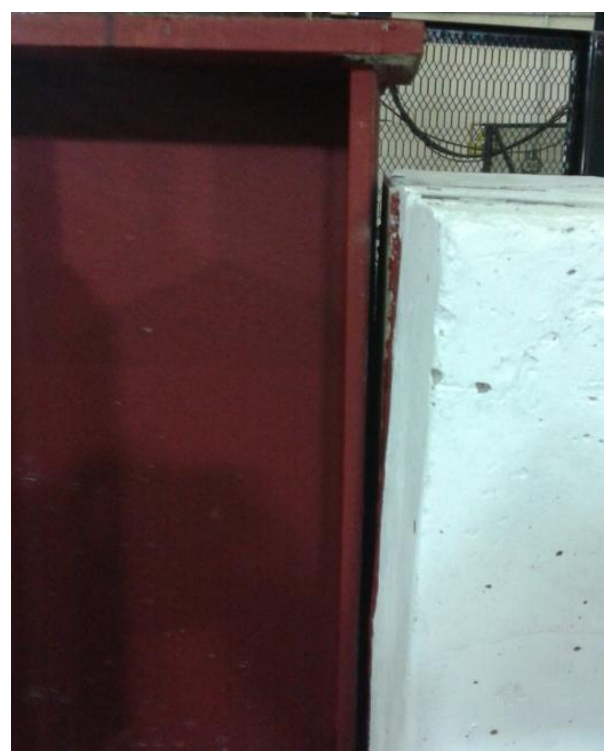

(b) Y-shaped Connectors

Fig.(16) Separation between the steel beam and the

\section{Conclusions}

The main purpose of this paper is to investigate the behavior of the separated Y-shaped shear connectors using push out tests. Six push-out tests were performed on the proposed shear connector according to EC4. The main investigated variables in this study were the effect of Y-shaping, the thickness, the height of the shear connector and the existence of a hole. Other parameters such as the connector length, concrete strength and slab geometry were kept the same for all specimens.

From the current experimental tests, the following points can be concluded:

1- The proposed separated Y-shaped shear connectors have higher resistance compared to the conventional perfobond connectors by about $25 \%$, for the specimens in this study.

2- The Y-shaping increases the capacity of non-holed straight connector by about $28 \%$ and the perfobond connector by about $23 \%$, for the current studied specimens. 
3- The Y-shaping improves the connector initial stiffness, and improves its behavior after peak load due to the effect of the arms of the Y-shape.

4- The arms of the Y-shape minimize the separation between the steel beam and the concrete slabs.

5- Increasing the thickness of the connector improves significantly the shear capacity of the Yshaped connector, but with some loss of ductility.

6- Increasing the height of the connector results in an increase in the shear capacity and ductility of the Y-shaped connector.

7- Adding a hole, for the studied specimens, did not affect significantly the shear capacity of the Yshaped connector (only 7\%) unlike the perfobond connector which gains about $12 \%$ in its shear capacity.

8- In case of no transverse rebars are used to pass through the connector holes, there is no need to make a hole in the $\mathrm{Y}$-shaped connector as its contribution to the connector capacity is not remarkable.

9- The failure patterns of all specimens are related to concrete crushing. However, the Y-shaped connectors show better load distribution along the concrete slab.

Finally, it was demonstrated that the proposed separated Y-shaped connector has more ductility and shear resistance compared to the conventional perfobond connector. Also it has more resistance to pull out forces and more economic.

\section{Acknowledgements}

The authors gratefully acknowledge all participants in this study and the support provided in the Reinforced Concrete and Heavy Structures Laboratory of the Faculty of Engineering, Tanta University, Egypt, where the tests were conducted.

\section{References}

[1] Ollgaard JG, Slutter RG, Fisher JW. Shear strength of stud connectors in lightweight and normalweight concrete. Eng J, AISC 1971;8(2):55-64.

[2] Oehlers, D. J. \& Johnson, R. P. The strength of stud shear connections in composite beams. Struct. Engr, 6511(2) (June 1987) 44-48.

[3] M.A. Dabaon, M.F. Hassanien. Behaviour of shear connectors using normal and high strength concrete: Part (I): experimental study. The 11th international colloquium structural and geotechnical engineering, Ain shams university, 2005.

[4] Ahn JH, Kim SH, Jeong YJ. Fatigue experiment of stud welded on steel plate for a new bridge deck system. Steel Compos Struct 2007;7(5):391-404.

[5] Pashan A. Behavior of channel shear connectors: Push-out tests. M.Sc. thesis. Canada: University of Saskatchewan; 2006.

[6] S.E. Abd-Rabou and M.A Dabaon,. Comparison between the theoretical and experimental investigation of composite beams with spiral shear connectors. Mansoura engineering journal $(M E J)$ vol.20, No.1, 1995.

[7] Mungwa JJ, Foudjet A, Hentges G (1999). Experimental study of a composite wood-concrete beam with the INSA-Hilti new flexible shear connector. Constr. Build. Mater, 13: 371-382.

[8] ZellnerW. Recent designs of composite bridges and a new type of shear connectors. Composite construction in steel and concrete. NY: American Society of Civil Engineers; 1987.

[9] Oguejiofor EC, Hosain MU. Numerical analysis of push-out specimens with Perfobond rib connectors. Computers and Structures 1997;62(4): 617-24.

[10] Machacek J, Studnicka J. Perforated shear connector. Steel and Composite Structures 2002;2(1):51-66. 
[11] Medberry SB, Shahrooz BM. Perfobond shear connector for composite construction. AISC Journal, Chicago 2002;1:2-12.

[12] Al-Darzi SYK, Chen AR, Liu YQ. Development of new hole shape of perfobond shear connectors, parametric study. In: Eligehausen R, Fuchs G, Grosser P, editors. Proceedings of the 2nd international symposium on connection between steel \& concrete. University of Stuttgart; 2007. p. 1401_13.

[13] Marecek J, Samec J, Studnicka J. Numerical analysis of Perfobond shear connector. In: Proceedings of the 4th international conference on advanced engineering design. 2004.

[14] J.da.C. Vianna, L.F. Costa-Neves, P.C.G. da S. Vellasco, S.A.L. de Andrade. Experimental assessment of Perfobond and T-Perfobond shear connectors' structural response. $J$ Constr SteelRes 2009;65:408-421.

[15] Isabel Valente, Paulo J.S. Cruz. Experimental analysis of Perfobond shear connection between steel and lightweight concrete. J ConstrSteel Res 2004; 60:465-479.

[16] J.P.S. Candido-Martins, L.F. Costa-Neves, P.C.G. da S. Vellasco. Experimental evaluation of the structural response of Perfobond shear connector. Engineering Structures 2010;32:19761985.

[17] Veríssimo GS, Valente I, Paes JLR, Cruz PJS, Fakury RH. Design and experimental analysis of a new shear connector for steel and concrete composite structures In: Cruz PJS, Frangopol DM, Neves LC, editors. Proceedings of the $3^{\text {rd }}$ international conference on bridge maintenance, safety, management, lifecycle performance and cost. 2006.

[18] Kim SH, Choi KT, Park SJ, Park SM, Jung CY. Experimental shear resistance evaluation of Ytype perfobond rib shear connector. J Constr Steel Res 2013;82:1-18.

[19] Kim SH, Park SJ, HeoWH, Jung CY. Shear resistance characteristic and ductility of Ytypeperfobond rib shear connector. Steel Compos Struct 2014 (in press).

[20] Kim SH, Heo WH, Woo SK, Jung CY, Park SJ. End-bearing resistance of Y-type perfobond rib according to rib width-height ratio.J Constr Steel Res 2014;103:101-116

[21] ENV 1994-2. Eurocode-4: Design of composite steel and concrete structures, Part 2: Composite bridges. CEN; 1997.

[22] Johnson, R.P. (1971), Composite Structures of Steel and Concrete Vol1, Beams, Slabs, Columns and Frames for Building, Oxford, Blackwell Scientific Publications.

[23] ENV 1992-1-1. Eurocode-2: Design of concrete structures, Part1: General rules and rules for building. CEN; 1992. 